ఠ

ORIGINAL RESEARCH

\title{
Acute effects of single and multiple level thoracic manipulations on chronic mechanical neck pain: a randomized controlled trial
}

This article was published in the following Dove Press journal:

Neuropsychiatric Disease and Treatment

12 January 2015

Number of times this article has been viewed

Rungthip Puntumetakul ${ }^{1,2}$

Thavatchai Suvarnnatol,3

Phurichaya Werasirirat ${ }^{1}$

Sureeporn Uthaikhup ${ }^{2}$

Junichiro Yamauchi ${ }^{4,5}$

Rose Boucaut ${ }^{6}$

'School of Physical Therapy, Faculty of Associated Medical Sciences,

${ }^{2}$ Research Center in Back, Neck, Other Joint Pain and Human Performance, ${ }^{3}$ Physical Therapy Unit, Srinagarind Hospital, Faculty of Medicine, Khon Kaen University, Khon Kaen, Thailand; ${ }^{4}$ Graduate School of Human Health Sciences, Tokyo Metropolitan University, ${ }^{5}$ Future Institute for Sport Sciences, Tokyo, Japan; ${ }^{6} \mathrm{School}$ of Health Sciences (Physiotherapy), University of South Australia, Adelaide, SA, Australia
Correspondence: Rungthip Puntumetakul School of Physical Therapy, Faculty of Associated Medical Sciences, Khon Kaen University, 123 Mittraphap Road, Meang District, Khon Kaen, 40002, Thailand

Tel +66 43202085

Email rungthiprt@gmail.com
Background: Thoracic spine manipulation has become a popular alternative to local cervical manipulative therapy for mechanical neck pain. This study investigated the acute effects of singlelevel and multiple-level thoracic manipulations on chronic mechanical neck pain (CMNP).

Methods: Forty-eight patients with CMNP were randomly allocated to single-level thoracic manipulation (STM) at T6-T7 or multiple-level thoracic manipulation (MTM), or to a control group (prone lying). Cervical range of motion (CROM), visual analog scale (VAS), and the Thai version of the Neck Disability Index (NDI-TH) scores were measured at baseline, and at 24-hour and at 1-week follow-up.

Results: At 24-hour and 1-week follow-up, neck disability and pain levels were significantly $(P<0.05)$ improved in the STM and MTM groups compared with the control group. CROM in flexion and left lateral flexion were increased significantly $(P<0.05)$ in the STM group when compared with the control group at 1-week follow-up. The CROM in right rotation was increased significantly after MTM compared to the control group $(P<0.05)$ at 24-hour follow-up. There were no statistically significant differences in neck disability, pain level at rest, and CROM between the STM and MTM groups.

Conclusion: These results suggest that both single-level and multiple-level thoracic manipulation improve neck disability, pain levels, and CROM at 24-hour and 1-week follow-up in patients with CMNP.

Keywords: thoracic manipulation, neck disability, pain level, neck pain

\section{Introduction}

Neck pain is a common problem in the general population. The prevalence of neck pain ranges from $16.7 \%$ to $75.1 \% .{ }^{1,2}$ Mechanical neck pain is one of the most common neck disorders. The source of pain may arise from many structures within the cervical spine and can develop into chronic pain. ${ }^{3}$ In the current study, mechanical neck pain was defined as pain in the area between the neck and shoulder regions, where neck movement or palpation of the cervical region could provoke symptoms. Cervical manipulation has been widely used for managing mechanical neck pain. ${ }^{4-10}$ However, manipulation of the cervical spine can be associated with minor adverse effects, such as local discomfort, headache, dizziness, and nausea, or serious complications such as radiculopathy, myelopathy, and stroke. ${ }^{11}$ Thoracic spine manipulation has therefore become popular as an alternative treatment for mechanical neck pain as it leads to fewer complications. ${ }^{12-16}$ Recent studies demonstrated that multiple-level thoracic manipulation (MTM) can reduce pain in patients with mechanical neck pain. ${ }^{12-16}$ However, some side effects of spinal manipulative therapy are relatively 
common in clinical practice. MTM can also cause adverse effects, such as aggravation of symptoms, stiffness, muscle spasm, headache, radiating discomfort, fatigue, dizziness, and nausea in some cases. ${ }^{13,17}$

Single-level thoracic manipulation (STM) may be another option for treatment of mechanical neck pain. Fernandez de las Penas et al report that STM (T4) improves mechanical neck pain. ${ }^{18}$ The T6-T7 intervertebral level has the narrowest and roundest spinal canal ${ }^{19}$ and is the most vulnerable neural tension area. ${ }^{20}$ Improvement in mobility of T6-T7 may provide a greater translation movement, resulting in reduced tension of the dural ligament and decreased neural tissue tension. Thus, manipulation at this level may reduce symptoms in patients with neck pain. Suvarnnato et al have also demonstrated that STM at T6-T7 can reduce pain and increase the cervical range of motion (CROM) in patients with chronic neck pain. ${ }^{21}$

It appears that patients with mechanical neck pain are likely to respond to STM and may have less adverse effects than MTM. No previous study has reported adverse effects of STM in patients with mechanical neck pain. However, it is unknown whether STM is as effective as MTM for reducing pain and increasing CROM. Therefore, the current study aimed to evaluate the short-term effects of STM (T6-T7) and MTM on pain and CROM. If STM at T6-T7 is shown to be as effective as MTM, this technique may allow clinicians to minimize adverse effects following spinal manipulation in patients with mechanical neck pain.

\section{Materials and methods}

\section{Participants}

Forty-eight participants (aged 18-59 years) with chronic mechanical neck pain (defined as pain in the area between the neck and shoulder regions) and in whom neck movement or palpation of the cervical region could provoke their symptoms, ${ }^{18}$ were recruited from the Physical Therapy Unit, Srinagarind Hospital, Faculty of Medicine, Khon Kaen University, Thailand. Each participant in the study was recruited by the physicians. To be eligible for the study, participants had to meet three criteria: neck pain with or without unilateral upper extremity symptoms of at least 3 months' duration; a score $\geq 10 / 100$ on the Thai version of the Neck Disability Index (NDI-TH); and neck pain provoked by sustained neck postures or neck movement. Participants were excluded if they reported any of the following: a history of whiplash injury; past cervical surgery or thoracic surgery; cervical radiculopathy; myelopathy (where at least two of the following were diminished indicating neurological involvement: myotomal strength, sensation, or reflexes); past spinal manipulative therapy; a serious spinal condition, such as infection, tumor, osteoporosis, spinal fracture, or spondylolisthesis; hypermobility of the thoracic spine; heart disease; meningitis; or pregnancy. The participants were asked to stop other treatments, ie, medication, exercise, modality, such as hot/cold pack, and other manual therapy during the study.

\section{Procedures}

An assessor-blinded, randomized controlled trial was used to determine the short-term effects of STM and MTM on chronic mechanical neck pain. The research protocol was approved by the research ethics committee for human research at Khon Kaen University. All participants were asked to sign an informed consent form before participating in the study.

One physiotherapist with more than 4 years of clinical experience in manual therapy and one assessor were involved in the study. Participants were initially screened by a rehabilitation medicine doctor. All eligible participants were asked to complete the NDI-TH and visual analog scale (VAS, 1-10 cm) questionnaires. A blinded assessor then measured the active range of cervical motion using a CROM device (Performance Attainment Associates, Lindstrom, MN, USA). A total of 54 patients with neck pain were screened for eligibility in the current study, and after screening by the doctor and completing the questionnaire, 48 eligible patients were enrolled. The exclusion criteria included age younger than 18 years $(n=1)$, NDI-TH less than $10 \%(n=3)$, and positive neurological signs $(n=2)$. The 48 patients were randomly allocated to an MTM group, an STM group, or a control group by block randomization with a block size of three and six (Figure 1).

The participants in each group received treatment from the same physical therapist. All outcomes, ie, CROM, NDI-TH and VAS scores, and any adverse effects, such as headache, local soreness, or nausea caused by thoracic manipulation were measured and recorded by another researcher who was blinded to the treatment group allocation.

\section{Interventions}

Single-level versus multiple-level thoracic manipulation The therapist applied a thoracic screw thrust to a restricted segment of the thoracic spine as described by Maitland et $\mathrm{al}^{22}$ (Figure 2A). The participants were asked to lie in a prone position with their head over the hole in a treatment couch. They then received either SMT directed to both sides of the T6-T7 zygapophyseal joints or MTM directed to both 


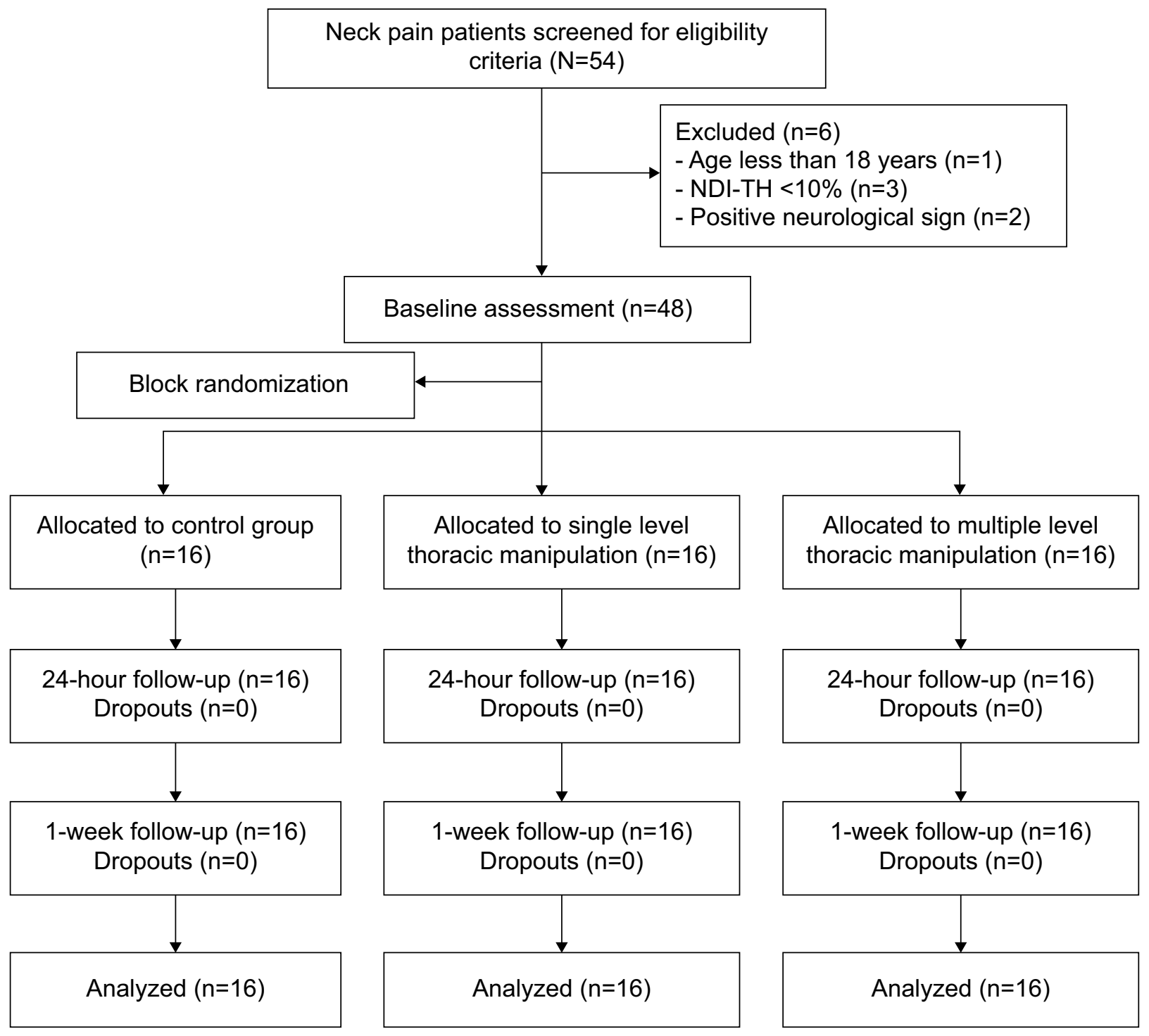

Figure I Flow diagram of subject recruitment throughout the course of the study. Abbreviation: NDI-TH, Thai version of the Neck Disability Index.

A

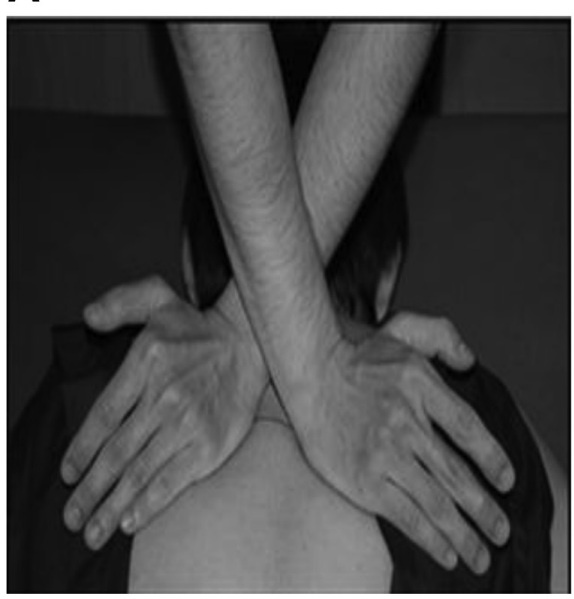

B

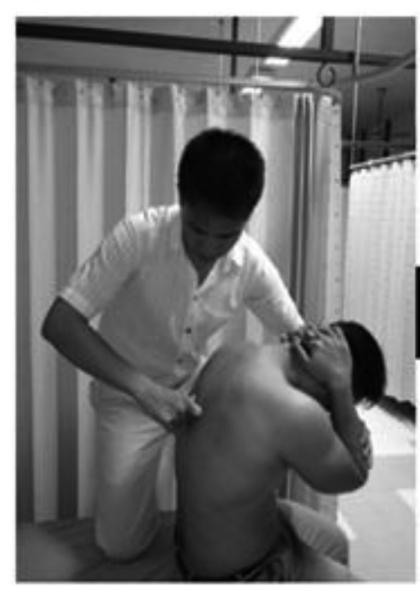

C

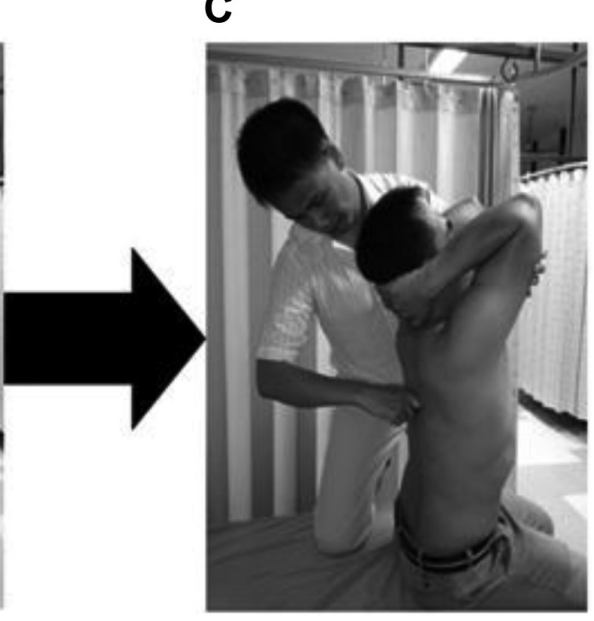

Figure 2 (A) Thoracic manipulation (screw thrust) (B) Segmental mobility in flexion testing and (C) Segmental mobility in extension testing. 
sides of the respective zygapophyseal joint as indicated by the segmental examination (Figure 2B-C). They were instructed to perform a deep inhalation and exhalation. The therapist applied a thoracic screw thrust. The therapist listened for a cracking sound during the thoracic manipulation. If this was not heard, the participant was repositioned, and the same manipulation was repeated. This procedure was performed for a maximum of two attempts. When a cracking sound occurred, the therapist moved on to the next segmental restriction from an upper level to a lower level for MTM.

\section{Control group}

The participants were asked to lie in a prone position on an experimental couch for 2 minutes. The therapist's hands were placed over the level of the thoracic zygapophyseal joint while the subject took a deep inhalation and exhalation without any treatment.

\section{Outcome measurements}

As a primary outcome, the perceived level of disability due to neck pain was assessed with the NDI-TH. This instrument consists of ten sections, including seven sections related to activities of daily living, two sections related to pain, and one section related to concentration. The score for each section is from 0 to 5 , with 0 representing the highest level of function and 5 representing the lowest level of function. Total NDI-TH scores are shown as a percentage. A high score corresponds to a higher degree of disability. The internal consistency of the NDI-TH is high. ${ }^{23}$

The secondary outcome was the perception of neck pain measured by the VAS. All participants recorded their VAS pain level at rest as the baseline, and at 24-hour and 1-week follow-up. The VAS was a $10 \mathrm{~cm}$ line anchored with a " 0 " representing no pain and " 10 " representing the worst pain imaginable. The VAS is a highly reliable method for measurement of pain $(\operatorname{ICC}(3,1)=0.97)$ and a valid tool for reliably assessing pain intensity at rest. ${ }^{24-26}$ The CROM was measured using the CROM device, which is highly reliable, with an intrarater reliability ranging from 0.91 to $0.95 .{ }^{27} \mathrm{Each}$ participant was asked to complete a questionnaire regarding side effects after manipulation. The questionnaire asked if they had experienced any unwanted effects after manipulation, and if so, the type of side effect, time onset, duration, and severity.

\section{Statistical analysis}

All data are presented as the mean \pm standard deviation. The pretreatment and posttreatment neck disability, pain level at rest, and CROM were compared between groups using mixed-model, repeated-measures analysis of variance. The hypothesis of interaction (group $\times$ time) existed between the groups for each measure. The proportions of participants reporting side effects in each group were analyzed using the chi-square test. A $P$-value of less than 0.05 was considered to be statistically significant.

\section{Results}

The baseline characteristics of the participants are shown in Table 1. No significant $(P>0.05)$ differences were seen in any of the demographic data, pain at rest, NDI-TH, and CROM between the three study groups. However, there were four males and 12 females in the MTM group and five

Table I Baseline characteristics in the current study

\begin{tabular}{|c|c|c|c|c|}
\hline \multirow[t]{2}{*}{ Source } & $\begin{array}{l}\text { Multiple TM } \\
(n=16)\end{array}$ & $\begin{array}{l}\text { Single TM } \\
(n=16)\end{array}$ & $\begin{array}{l}\text { Control } \\
(n=16)\end{array}$ & $\begin{array}{l}\text { Total } \\
(n=48)\end{array}$ \\
\hline & Mean \pm SD & Mean \pm SD & Mean \pm SD & Mean \pm SD \\
\hline Age (years) & $26.56 \pm 8.24$ & $25.94 \pm 9.69$ & $27.13 \pm 7.46$ & $26.54 \pm 8.35$ \\
\hline Weight (kg) & $60.13 \pm 14.13$ & $51.19 \pm 8.42$ & $62.88 \pm 13.75$ & $58.06 \pm 13.12$ \\
\hline Height $(\mathrm{cm})$ & $162.50 \pm 9.75$ & $162.38 \pm 8.49$ & $|66.3| \pm 8.03$ & $163.73 \pm 8.79$ \\
\hline BMI $\left(\mathrm{kg} / \mathrm{m}^{2}\right)$ & $22.62 \pm 4.07$ & $19.36 \pm 2.49$ & $22.63 \pm 4.20$ & $21.53 \pm 3.91$ \\
\hline NDI-TH (\%) & $27.63 \pm 11.64$ & $26.38 \pm 9.04$ & $23.50 \pm 9.92$ & $25.84 \pm 10.18$ \\
\hline Pain level at rest: & $5.22 \pm 1.27$ & $5.21 \pm 1.12$ & $5.29 \pm 1.16$ & $5.24 \pm 1.16$ \\
\hline \multicolumn{5}{|l|}{ VAS (cm) } \\
\hline \multicolumn{5}{|l|}{ CROM (degrees) } \\
\hline Flexion & $53.37 \pm 14.84$ & $57.41 \pm 10.02$ & $51.60 \pm 10.39$ & $54.13 \pm 11.95$ \\
\hline Extension & $58.04 \pm 12.84$ & $61.41 \pm 10.16$ & $57.25 \pm|2.7|$ & $58.90 \pm 11.85$ \\
\hline Right lateral flexion & $38.70 \pm 9.08$ & $37.20 \pm 6.95$ & $38.79 \pm 6.40$ & $38.23 \pm 7.44$ \\
\hline Left lateral flexion & $36.25 \pm 8.80$ & $34.87 \pm 5.69$ & $37.12 \pm 10.36$ & $36.08 \pm 8.37$ \\
\hline Right rotation & $59.12 \pm 9.77$ & $58.66 \pm 13.30$ & $60.91 \pm 7.37$ & $59.56 \pm 10.26$ \\
\hline Left rotation & $55.99 \pm 10.39$ & $54.16 \pm 8.84$ & $56.08 \pm 11.74$ & $55.41 \pm 10.21$ \\
\hline
\end{tabular}

Abbreviations: BMI, body mass index; CROM, cervical range of motion; NDI-TH, Thai version of the Neck Disability Index; SD, standard deviation; TM, thoracic manipulation; VAS, visual analog scale. 
males and eleven females in the STM group, so there was a sex imbalance in favor of females in the MTM and STM groups. The demographics of the three groups were similar, with no significant difference between groups across all categories excluding sex. A previous study involving cervical manipulation demonstrated that males and females have similar outcomes for reductions in pain intensity and painrelated disability. ${ }^{28}$

The NDI-TH and pain level at rest were significantly decreased after STM and MTM at 24-hour and 1-week follow-up when compared with baseline values $(P<0.05$, Figure 3). The NDI-TH and pain level at rest in the STM and MTM groups were significantly lower than in the control group at 24-hour and 1-week follow-up $(P<0.05$, Figure 3$)$. The reduction in degree of NDI-TH and the pain level at rest were similar between the MTM and STM groups at both time points $(P>0.05)$.

There was no significant difference with regard to CROM in the STM and MTM groups at 24-hour and 1-week follow-up $(P>0.05)$ when compared with baseline. The MTM group improved significantly in right rotation at 24 hours compared with the control group. STM significantly improved flexion and left lateral flexion at one-week follow-up when compared with the control group. There were no significant differences in CROM between the STM and MTM groups at either follow-up time point $(P>0.05$, Table 2).

The specific adverse effects reported by the MTM group included headache $(\mathrm{n}=2,12.5 \%)$, local soreness immediately after treatment $(\mathrm{n}=7,43.8 \%)$, and local soreness 24 hours later $(n=3,18.8 \%)$. Participants in the STM group reported only local soreness $(n=1,6.3 \%)$ immediately after treatment and 24 hours later. The chi-square test demonstrated that local

A

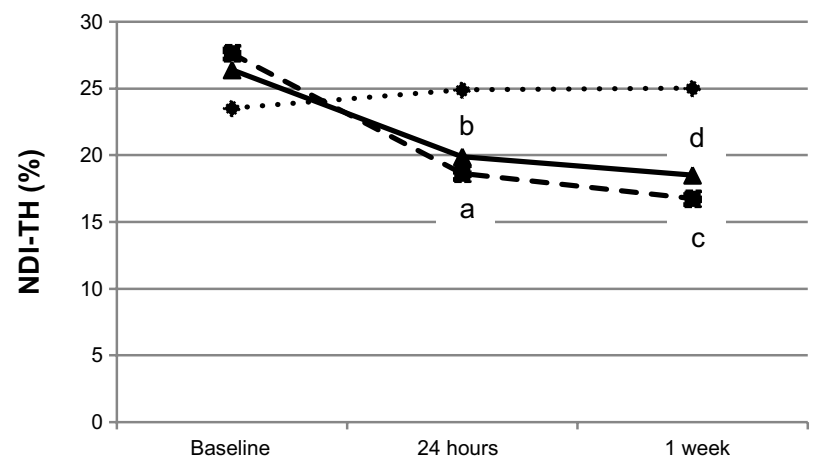

soreness was significantly worse $(P=0.014)$ in the MTM group $(\mathrm{n}=7)$ than in the STM group $(\mathrm{n}=1)$ immediately after treatment. None of the participants reported adverse effects at the 1-week follow-up.

\section{Discussion}

Our findings show that the NDI-TH and pain level at rest in patients with chronic mechanical neck pain were significantly decreased at 24 hours and 1 week after STM and MTM. CROM was improved after STM and MTM. Right rotation was improved significantly in the MTM group at the 24-hour follow-up when compared with the control group. STM significantly improved flexion and left lateral flexion at 1-week follow-up compared with the control group.

The reason why STM and MTM caused different improvements at different time points remains unclear. One possible explanation is that MTM was performed at several levels of the thoracic spine, whereas STM was performed on only one level. Further research is required to clarify this finding.

There are three possible explanations for the effects of STM and MTM on the reduction of pain level at rest. First, spinal manipulation may provide an adequate stimulus to activate the descending pain inhibitory system projecting from the dorsal periaqueductal gray via nuclei in the ventrolateral medulla to the spinal cord, and this mechanism could result in hypoalgesic effects in distant areas. ${ }^{29,30} \mathrm{Sec}-$ ond, spinal manipulation may affect pain processing in the spinal cord via the gate control theory. ${ }^{31}$ Third, the spinal manipulation procedure may induce reflex inhibition of pain or reflex muscle relaxation by modifying the discharge of proprioceptive group I and II afferents. ${ }^{32}$ Mechanical stimulation induced by spinal manipulation may decrease pain in

B

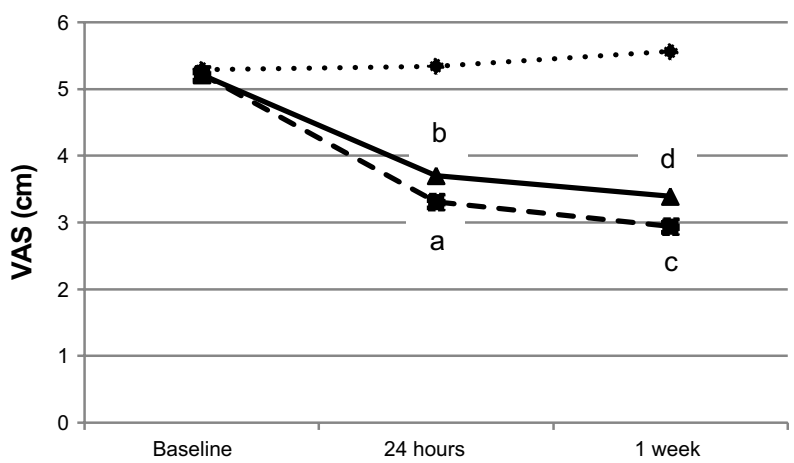

Figure 3 (A) NDI-TH, baseline and after treatment; (B) pain level at rest, baseline and after treatment.

Notes: aSignificant difference between baseline and 24 hours post-intervention $(P<0.005)$ for MTM; ${ }^{b}$ significant difference between baseline and 24 hours post-intervention $(P<0.005)$ for STM; 'significant difference between baseline and I week post-intervention $(P<0.005)$ for MTM; dsignificant difference between baseline and I week postintervention $(P<0.005)$ for STM. $\bullet$ represents the control group, $\mathbf{a}$ represents the MTM group, and $\mathbf{\Delta}$ represents the STM group.

Abbreviations: NDI-TH, Thai version of the Neck Disability Index; VAS, Visual Analog Scale; MTM, multiple-level thoracic manipulation; STM, single-level thoracic manipulation. 


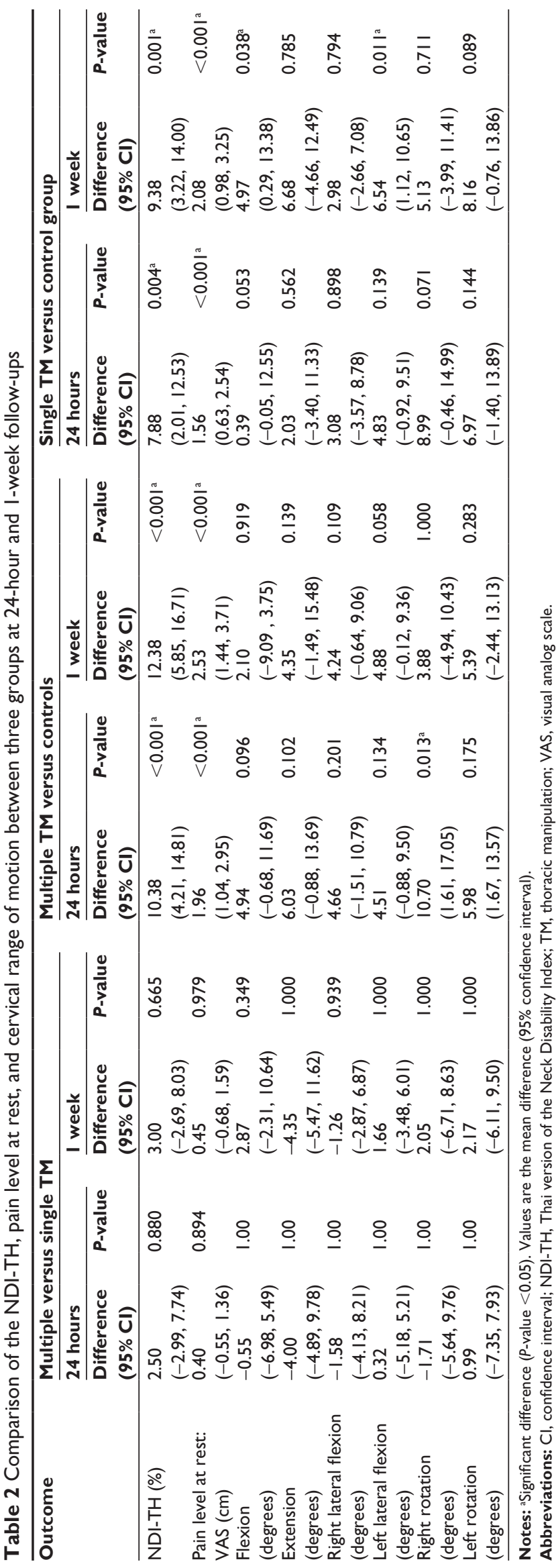

muscles that have their origins in the cervical and/or thoracic spine. ${ }^{33}$ Although some previous studies have reported that there may be a possible placebo effect of having hand contact during performance of the interventions, ${ }^{21,34}$ our study did not find this effect in the control group (Figure 3).

Postural abnormalities arising from a number of issues may contribute to discomfort in the cervical region in both adults and children. ${ }^{35-37}$ Both STM and MTM have been shown to increase CROM immediately and at follow-up 24 hours later in patients with chronic mechanical neck pain. ${ }^{21}$ Previous studies ${ }^{38,39}$ show that the effects of thoracic manipulation could improve cervical mobility by altering the biomechanics of the thoracic spine. Since the segments of the thoracic spine are related to the cervical region, restoration of the normal biomechanics of the thoracic region by either STM or MTM could potentially lower the mechanical stress and increase the distribution of joint forces in the cervical spine, leading to an increase in CROM. ${ }^{38,39}$ Similarly, Cleland et al ${ }^{12,13}$ reported that MTM at the T4 level decreased pain and neck disability in patients with mechanical neck pain.

Changes in neck disability scores were $2.50 \%$ and $3.00 \%$ at 24 -hour and 1-week follow-up, respectively, by both manipulation methods and no significant difference was observed between STM and MTM. The difference in VAS scores for pain levels at rest was not significant in either group at 24-hour or 1-week follow-up. This suggests that both STM and MTM can improve NDI-TH and VAS scores in patients with chronic mechanical neck pain in a similar way. Although the lack of a significant difference in NDI-TH and VAS scores between the STM and MTM groups at either follow-up point might be due to the small size of the samples, we have performed the retrospective power of the test to determine the degree of power for the sample size in this study, and the power of the test in this study was greater than $90 \%$, suggesting that the nonsignificant difference in our results is acceptable, and the same mechanism of both techniques.

The nonsignificant difference in CROM between the STM and MTM groups at both follow-up time points may be due to the same mechanism of both techniques. The physical effects of thoracic manipulation on cervical mobility can alter the biomechanics of the thoracic spine, decreasing mechanical stress and improving the distribution of force on the cervical joints. ${ }^{38,39}$ Thus, it is possible that both techniques have inherent quality and can alter the biomechanics that can improve the CROM.

Patients receiving MTM had a few adverse effects, comprising local soreness $(n=7,43.8 \%)$ and headaches $(n=2$, 
$12.5 \%$ ), while STM caused local soreness in only one subject (6.3\%). Looking at previous studies that have investigated the prevalence of side effects of manipulation directed at the entire spine, one has reported that a variety of adverse effects occurred about $55 \%$ of the time after manipulation treatment. ${ }^{17}$ Cleland et $\mathrm{al}^{13}$ reported that the subjects who received thoracic manipulation had a number of adverse effects, including aggravation of symptoms (26.67\%), muscle spasm (3.33\%), and headache $(3.33 \%)$. It is known that spinal manipulation can increase soreness. ${ }^{40}$ Thus, STM had less adverse effects than MTM. It is possible that the number of techniques performed in MTM could lead to increased soreness compared with STM. Since STM had fewer adverse effects than MTM, and had comparable therapeutic effects, STM may be a better choice for treatment for chronic mechanical neck pain. ${ }^{13}$

We collected data only post-intervention at 24-hour and 1-week follow-up, so future studies should examine: the long-term effects of STM/MTM in patients with chronic mechanical neck pain; treatments conducted for more than one session and/or for a subgroup of patients with neck pain, such as those with whiplash injury, other trauma, or degenerative disc disease; the effects of thoracic manipulation in other treatment groups, eg, drug therapy or exercise; and the effects of this clinical intervention in a larger sample size.

\section{Conclusion}

The findings of this study show that both STM and MTM significantly and almost equally improved neck disability and resting pain levels, in patients with chronic mechanical neck pain, for up to 1 week. Since there were some adverse effects in subjects in the MTM group, STM may be a better choice for the treatment of chronic mechanical neck pain.

\section{Acknowledgment}

This study was supported by a grant from the Research Center in Back, Neck, Other Joint Pain and Human Performance, Khon Kaen University, Thailand.

\section{Disclosure}

The authors report no conflicts of interests in this work.

\section{References}

1. Fejer R, Ohm-Kyvik K, Hartvigsen J. The prevalence of neck pain in the world population: a systematic critical review of the literature. Eur Spine J. 2006;15(6):834-848.

2. Gummesson $\mathrm{C}$, Isacsson $\mathrm{SO}$, Isacsson $\mathrm{AH}$, et al. The transition of reported pain in different body regions: a one-year follow-up study. BMC Musculoskelet Disord. 2006;7(2):17.

3. Cote P, Cassidy JD, Carroll L. The Saskatchewan Health and Back Pain Survey. The prevalence of neck pain and related disability in Saskatchewan adults. Spine. 1998;23(15):1689-1698.
4. Gross AR, Kay TM, Kennedy C, et al. Clinical practice guidelines on the use of manipulation or mobilization in the treatment of adults with mechanical neck disorders. Man Ther. 2002;7(4): 193-205.

5. Hurwitz EL, Morgenstern H, Harber P, Kominski GF, Yu F, Adams AH A randomized trial of chiropractic manipulation and mobilization for patients with neck pain: clinical outcomes from the UCLA neck-pain study. Am J Public Health. 2002;92(10):1634-1641.

6. Martinez-Segura R, Fernandez-de-las-Penas C, Ruiz-Saez M, LopezJimenez C, Rodriguez-Blanco C. Immediate effects on neck pain and active range of motion after a single cervical high-velocity lowamplitude manipulation in subjects presenting with mechanical neck pain: a randomized controlled trial. J Manipulative Physiol Ther. 2006; 29(7):511-517.

7. Hoving JL, De Vet HC, Koes BW, et al. Manual therapy, physical therapy, or continued care by the general practitioner for patients with neck pain: long-term results from a pragmatic randomized clinical trial. Clin J Pain. 2006;22(4):370-377.

8. Kanlayanaphotporn R, Chiradejnant A, Vachalathiti R. The immediate effects of mobilization technique on pain and range of motion in patients presenting with unilateral neck pain: a randomized controlled trial. Arch Phys Med Rehabil. 2009;90(2):187-192.

9. Gross A, Miller J, Sylva J, et al. Manipulation or mobilisation for neck pain: a Cochrane review. Man Ther. 2010;15(4):315-333.

10. Leaver AM, Maher CG, Herbert RD, et al. A randomized controlled trial comparing manipulation with mobilisation for recent onset neck pain. Arch Phys Med Rehabil. 2010;91(9):1313-1318.

11. Gross AR, Kay T, Hondras M, et al. Manual therapies for mechanical neck disorders: a systematic review. Man Ther. 2002;7(3):131-149.

12. Cleland JA, Childs MJD, McRae M, Palmer JA, Stowell T. Immediate effects of thoracic manipulation in patients with neck pain: a randomized clinical trial. Man Ther. 2005;10(2):127-135.

13. Cleland JA, Glynn P, Whitman JM, Eberhart SL, MacDonald C, Childs JD. Short-term effects of thrust versus non-thrust mobilization/ manipulation directed at the thoracic spine in patients with neck pain: a randomized clinical trial. Phys Ther. 2007;87(4):431-440.

14. Gonzalez-Iglesias J, Fernandez de las Penas C, Cleland JA, Alburquerque-Sendin F, Palomeque-del-Cerro L, Mendez-Sanchez R. Inclusion of thoracic spine thrust manipulation into an electrotherapy/thermal program for the management of patients with acute mechanical neck pain: a randomized clinical trial. Man Ther. 2008; 14(3):1-8.

15. Lau HMC, Wing Chiu TT, Lam TH. The effectiveness of thoracic manipulation on patients with chronic mechanical neck pain. A randomized controlled trial. Man Ther. 2011;16(2):141-147.

16. Puentedura EJ, Landers MR, Cleland JA, Mintken PE, Huijbregts $P$, Fernández-de-Las Peñas C. Thoracic spine thrust manipulation versus cervical spine thrust manipulation in patients with acute neck pain: a randomized clinical trial. J Orthop Sports Phys Ther. 2011;41(4):208-220.

17. Cagnie B, Vinck E, Beernaert A, Cambier D. How common are side effects of spinal manipulation and can these side effects be predicted? Man Ther. 2004;9(3):151-156.

18. Fernandez de las Penas C, Palomeque-del-Cerro L, RodriguezBlonco C, Gomez-Coneasa A, Miangolarra-Page JC. Changes in neck pain and active range of motion after a single thoracic spine manipulation in subjects presenting with mechanical neck pain: a case series. J Manipulative Physiol Ther. 2007;30(4):312-320.

19. Dommisse GF. Morphological aspects of the lumbar spine and lumbosacral region. Orthop Clin North Am. 1975;6(1):163-175.

20. Butler DS. Mobilization of the Nervous System. Melbourne, Australia: Churchill Livingstone; 1991.

21. Suvarnnato T, Puntumetakul R, Kaber D, et al. The effects of thoracic manipulation versus mobilization for chronic neck pain: a pilot randomized controlled study. J Phys Ther Sci. 2013;25(7):865-871.

22. Maitland G, Hengeveld E, Banks K, English K. Maitland's Vertebral Manipulation. 6th ed. Oxford, UK: Butterworth-Heinemann; 2000. 
23. Uthaikhup S, Paungmali A, Pirunsan U. Validation of Thai versions of the Neck Disability Index and Neck Pain and Disability Scale in patients with neck pain. Spine. 2011;36(21):E1415-E1421.

24. Bijur PE, Silver W, Gallagher JE. Reliability of the visual ana$\log$ scale for measurement of acute pain. Acad Emerg Med. 2001;8(12):1153-1157.

25. Bird SB, Dickson EW. Clinically significant changes in pain along the visual analog scale. Ann Emerg Med. 2001;38(6):639-643.

26. Gallagher EJ, Liebman M, Bijur PE. Prospective validation of clinically important changes in pain severity measured on a visual analog sale. Ann Emerg Med. 2001;38(6):633-638.

27. Suvarnnato T, Puntumethaku R, Boonprakop Y, Phadungkit S. Intratester reliability of three clinical methods of measuring active cervical range of motion in normal subjects: a preliminary study. $J$ Med Tech Phys Ther. 2010;22(2):160-166.

28. George SZ, Fritz JM, Childs JD, Brenan GP. Sex differences in predictors of outcome in selected physical therapy interventions of acute low back pain. J Orthop Sports Phys Ther. 2006;36(6):354-363.

29. Vicenzino B, Paungmali A, Buratowsky S, Wright A. Specific manipulative therapy treatment for chronic lateral epicondylalgia produces uniquely characteristic hypoalgesia. Man Ther. 2001;6(4):205-212.

30. Paungmali A, O’Leary S, Souvlis T, Vincenzino B. Hypoalgesic and symthoexcitatory effects of mobilization with movement for lateral epicondylalgia. Phys Ther. 2003;83(4):374-383.

31. Melzack R, Wall PD. Pain mechanisms: a new theory. Science. 1965;150:971-979.
32. Pickar JG. Neurophysiological effects of spinal manipulation. Spine J. 2002;2(5):357-371.

33. Gray H. Anatomy: Descriptive and Surgical. London, UK: Chartwell; 1991.

34. Bialosky JE, Bishop MD, George SZ, et al. Placebo response to manual therapy: something out of nothing? J Man Manip Ther. 2011;19(1): 11-19.

35. Perillo L, Femminella B, Farronato D, Baccetti T, Contardo L, Perinetti G. Do malocclusion and Helkimo Index $\geq 5$ correlate with body posture? J Oral Rehabil. 2011;38(4):242-252.

36. Perillo L, Esposito M, Contiello M, Lucchese A, Santini AC, Carotenuto M. Occlusal traits in developmental dyslexia: a preliminary study. Neuropsychiatr Dis Treat. 2013;9(8):1231-1237.

37. Perillo L, Esposito M, Caprioglio A, Attanasio S, Santini AC, Carotenuto M. Orthodontic treatment need for adolescents in the Campania region: the malocclusion impact on self-concept. Patient Prefer Adherence. 2014;19(8):353-359.

38. Edmondston SJ, Singer KP. Thoracic spine: anatomical and biomechanical considerations for manual therapy. Man Ther. 1997;2(3):132-143.

39. Norlander S, Nordgren B. Clinical symptoms related to musculoskeletal neck-shoulder pain and mobility in the cervico-thoracic spine. Scand $J$ Rehabil Med. 1998;30(4):243-251.

40. Senstad O, Leboeuf-Yde C, Borchgrevink C. Frequency and characteristics of side effects of spinal manipulative therapy. Spine. 1997;22(4):435-441.
Neuropsychiatric Disease and Treatment

\section{Publish your work in this journal}

Neuropsychiatric Disease and Treatment is an international, peerreviewed journal of clinical therapeutics and pharmacology focusing on concise rapid reporting of clinical or pre-clinical studies on a range of neuropsychiatric and neurological disorders. This journal is indexed on PubMed Central, the 'PsycINFO' database and CAS,

\section{Dovepress}

and is the official journal of The International Neuropsychiatric Association (INA). The manuscript management system is completely online and includes a very quick and fair peer-review system, which is all easy to use. Visit http://www.dovepress.com/testimonials.php to read real quotes from published authors. 